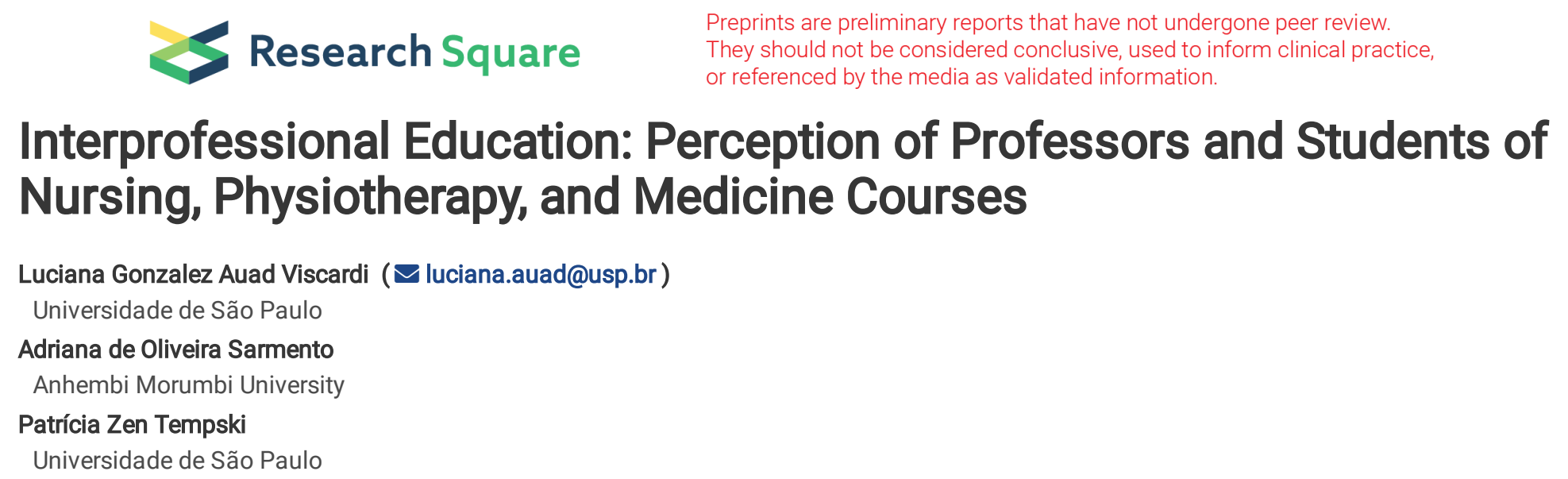

\section{Interprofessional Education: Perception of Professors and Students of Nursing, Physiotherapy, and Medicine Courses}

Luciana Gonzalez Auad Viscardi ( $\sim$ luciana.auad@usp.br)

Universidade de São Paulo

Adriana de Oliveira Sarmento

Anhembi Morumbi University

Patrícia Zen Tempski

Universidade de São Paulo

Research Article

Keywords: Interprofessional Education, Teamwork, Collaborative Practice, Training in Medicine, Training in Nursing, Training in Physiotherapy

Posted Date: January 6th, 2022

DOI: https://doi.org/10.21203/rs.3.rs-1217961/v1

License: (c) (i) This work is licensed under a Creative Commons Attribution 4.0 International License. Read Full License 


\section{Abstract Background}

The problems for training in interprofessional education (IPE) of health professionals for this new century are systemic: limitation in competencies for teamwork, persistent stratification of gender relations in the status of health workers, a focused emphasis on technical skills, difficulty in analysis and understanding of broader problematic issues of the context, sporadic instead of continuous care, quantitative and qualitative imbalances in the professional labor market, and fragility in leadership skills to improve the performance of the health system. This study evaluated the perception of students and teachers of health area courses at a private university in São Paulo regarding interprofessional education.

\section{Methods}

A sociodemographic questionnaire to delineate the participants' profile and the RIPLS questionnaire that assesses the attitudes and perceptions of students and professionals to determine their readiness for interprofessional learning were applied. RIPLS is proposed to measure the change in attitudes, the effects of different interventions, and the effectiveness of interventions in changing attitudes and perceptions.

\section{Results}

The main results were that training in Medicine and Nursing is easier for interprofessional education than that in Physiotherapy. By comparing the perception of the academic community regarding gender, we find that participating women are more available for teamwork and collaborative practices.

\section{Conclusion}

To improve the perception of students and teachers in collaborative practice, the need for a teacher training program on IPE principles and an early and more frequent insertion of IPE practices in the curricula of courses is evident.

\section{Introduction}

Comprehensive care is a complex process that demands considerable knowledge from different health professions [1]. The lack of collaboration and effective communication between health professionals has been cited as possible reasons for the poor quality of care. Studies have highlighted the need for teamwork, even though there are specificities of each health profession, the work should not happen in a disjointed way [2, 3], and the focus should be on meeting health needs [3].

The process of professional health training is in the historical phase of reforms aimed at strengthening health systems, with significant challenges for this new century. The problems for the training in interprofessional education (IPE) of health professionals for this new century are systemic: limited skills for teamwork, persistent stratification of gender relations in the status of health workers, emphasis focused on technical skills, difficulty in analysis and understanding of broader issues of context, sporadic instead of continuous care, quantitative and qualitative imbalances in the professional labor market, and weaknesses in leadership skills to improve the performance of the health system [4].

The foundations for IPE, defined as the learning that happens when two or more professions learn about, with, and among each other to improve collaboration and health outcomes [5], should begin in undergraduate education. Barr [6] states that the IPE is a proposal where professions learn together about working together and about the specificities of each one to improve the quality of patient care.

As a training proposal, Partners in Health (PIH) has been discussed in the last thirty years, initially in Canada and the United Kingdom and later in the United States and Europe, to stimulate health care improvement through teamwork. IPE principles apply both for the graduation of different health professions and for the continuing education of professionals who are components of a work team [7], requiring much more than sharing the same space [8].

Among the policies that discuss IPE, the UNI Program: A New Initiative in the Education of Health Professionals, of the 1990s, was an important initial milestone in that it proposed a paradigm shift in the education of these professionals from the criticism to the Flexnerian 
model of medical training, with the incorporation of the interdisciplinary and multidisciplinary perspectives, with approaches that are close to the theoretical-conceptual and methodological frameworks of IPE [9].

In 2010, the WHO published the "Framework for Action on IPE and Collaborative Practice (CP)." In this document, when multiple health professionals with different backgrounds provide comprehensive services, working with patients, families, and communities to provide the best quality of services in each setting [10], some mechanisms outline IPE at the practice level. These mechanisms are divided into educator and curricular mechanisms, which point to the need to prepare educators with good communication between participants, enthusiasm to carry out the work, and leaders responsible for coordinating educational activities and identifying barriers to progress [5].

From 2017, motivated by the agenda proposed by the Pan American Health Organization (PAHO), a Brazilian action plan for the implementation of IPE was prepared by the Ministry of Health (MH) in conjunction with the Ministry of Education (MEC), higher education institutions (HEIs), and the Brazilian Network of Education and Interprofessional Health Work (ReBETIS), organized into five lines of action, which include teacher development for IPE [11], reaffirming the importance that the basis is initiated even at the undergraduate level.

Reeves [12] highlights the relevance of the teacher's competence as a mediator in learning situations anchored in IPE. This competence encompasses a set of dimensions ranging from previous experiences, intentionality for interprofessional group work, flexibility and creativity to experience situations in a shared manner with students, to teacher involvement and commitment to IPE.

Another challenge is the resistance to breaking the current training model. Professionals continue to be trained separately to work together in the future, which is inconsistent and brings significant losses to the quality of care offered within the Health Unic System (HUS) [13].

However, there is a need to evaluate the IPE on learning outcomes and study the best ways to implement it in universities [2]. For this, it is essential to know the perception of students and teachers of health courses regarding the benefits and values of IPE for the training of a professional with greater competence and ethics for their work. This is important as it can subsidize curriculum changes, enabling improvement in educational strategies and health services and contributing to the construction of knowledge in this area. This study evaluates the perception of students and teachers of Nursing, Physiotherapy, and Medicine courses of a private university in São Paulo regarding interprofessional education.

\section{Methods}

This is a mixed exploratory cross-sectional study (quantitative and qualitative) on the perception and experience of interprofessional education by students and teachers at a private university in São Paulo regarding the health area courses. The Research Ethics Committee of the Medical School of the Universidade de São Paulo approved the research (No. 3.011.083).

A total of 310 students enrolled in the penultimate and last semester of the Nursing, Physiotherapy, and Medicine courses, and 85 teachers who teach classes for these courses and periods were included in the study. All participants signed the free and informed consent form (ICF), ensuring confidentiality regarding the identity and origin of the respondent. Participation was voluntary, and there were no gains or advantages of any nature; similarly, the non-participation did not result in damage. As inclusion criteria, student participants should be regularly enrolled in the final year of the Nursing, Physiotherapy, and Medicine courses. The teacher participants should teach disciplines/supervised internship/internship for students in the final year of their respective courses. The exclusion criteria were as follows: students who had not signed the consent form had a locked registration or were dismissed, teachers who were not regularly enrolled in the last two semesters of the courses, or visiting teachers.

\section{Research Instruments}

\section{Sociodemographic questionnaire}

A sociodemographic questionnaire was applied to delineate the participants' profiles regarding age, gender, year of graduation, and area of work.

\section{Readiness for Interprofessional Learning Scale (RIPLS) questionnaire}

The RIPLS questionnaire assesses the attitudes and perceptions of students and professionals to determine their readiness for interprofessional learning. RIPLS is proposed to measure the change in attitudes, the effects of different interventions, and the effectiveness of interventions on changes in attitudes and perceptions. The original version was published by Parsell and Bligh [14] with 29 items and was cross-culturally adapted into Portuguese by Peduzzi et al. [15]. The Portuguese version used in this research presents 27 items (questions 18 and 20 were excluded from the original). The respondents indicated their answers on a Likert-type scale ranging from $1=I$ totally disagree, $2=$ I disagree, 3 = I neither agree nor disagree, 4 = I agree, to 5 = I totally agree. Thus, the higher the score, the higher the agreement with the item 
and the stronger the attitudes and availability for interprofessional learning. The factor structure recommended by Peduzzi et al. [15] was adopted.

\section{Data Collection}

The universe of final-year students of the courses studied was accessed by electronic mail and in person at the end of an activity in the classroom, with the help of teachers.

The research, its objectives, and methods were presented to the students. Those who agreed to participate received the link to the questionnaire in the Google forms tool (Google LLC, CA, USA), an electronic platform for data collection and analysis. Participation was voluntary and conditioned on the signature of the ICF. After accepting the ICF, the participants had access to a sociodemographic questionnaire, two open questions, and the RIPLS questionnaire. Data collection was performed in the period from August 2019 to July 2020.

\section{Data Analysis}

Statistical Package for the Social Statistics (SPSS) software (version 24; SPSS, Chicago, IL, USA) was used for quantitative analysis. Data were presented as mean and standard deviation. The Kolmogorov-Smirnov and Levene tests were used to assess sample distribution and homogeneity, respectively, for all variables in each group. The comparison between groups with three or more independent variables was conducted using ANOVA test with Tukey's post hoc; for the comparison of two independent samples, the Student's T-test was used. MannWhitney U test was used to compare teachers and students. For all the analyses, a significance level of $p \leq 0.05$ was adopted.

\section{Results}

\section{Sample Description}

The study sample consisted of 310 students enrolled in the final year of the Nursing, Physiotherapy, and Medicine courses of a private university in São Paulo, 48 students did not answer the survey, and six students had deferred the course (Figure 1). The universe of teachers who teach the final-year classes of the aforementioned courses of the same university consisted of 85 teachers; 17 did not respond to the survey, as illustrated in Figure 2.

The study included 256 students and 68 teachers, with 72 (28\%) students and 22 (32\%) teachers from the Physiotherapy course, 69 (27\%) students and 29 (43\%) teachers from the Medicine course, and 115 (45\%) students and 17 (25\%) teachers from the Nursing course (Table 1$).$ Regarding gender, 200 (78\%) of the student respondents are female, and 56 (22\%) are male. Of the 68 teacher respondents, 52 (76\%) are female, and 16 (24\%) are male (Table 1$)$.

Regarding the students' age range, 178 (70\%) are between 20 and 24 years old, 52 (20\%) between 25 and 29 years old, 14 (5\%) between 30 and 34 years old, seven (3\%) between 35 and 39 years old, and five (2\%) above 40 years old. As for the teachers' age bracket, 11 (16\%) are between 30 and 34 years old, 15 (22\%) are between 35 and 39 years old, and 42 (62\%) are above 40 years old (Table 1). As for the semester in which they are enrolled, $114(45 \%)$ students are in the penultimate semester, and 142 (55\%) are in the last semester. Regarding the students who have financial aid, 118 (46\%) students do not have any aid program, 35 (13\%) are scholarship students, 50 (20\%) are ProUni students, 50 (20\%) have FIES, and three (1\%) are quota holders (Table 1 ).

Regarding the time that the teachers have been teaching, 15 (22\%) have up to two years' experience, 18 (27\%) have from three to five years, 9 $(13 \%)$ have from six to eight years, and $26(38 \%)$ have more than nine years (Table 1$)$. 
Table 1

Characterization of the sample.

\begin{tabular}{|c|c|c|}
\hline & Students & Teachers \\
\hline \multicolumn{3}{|l|}{ Course } \\
\hline Nursing & 115 & 17 \\
\hline Physiotherapy & 72 & 22 \\
\hline Medicine & 69 & 29 \\
\hline \multicolumn{3}{|l|}{ Sex } \\
\hline Fem. & 200 & 52 \\
\hline Male & 56 & 16 \\
\hline \multicolumn{3}{|l|}{ Age Group } \\
\hline $20-24$ years old & 178 & 0 \\
\hline $25-29$ years old & 52 & 0 \\
\hline $30-34$ years old & 14 & 11 \\
\hline $35-39$ years old & 7 & 15 \\
\hline Over 40 years old & 5 & 42 \\
\hline \multicolumn{3}{|c|}{ Semester of Enrollment } \\
\hline Penultimate & 114 & \\
\hline Last & 142 & \\
\hline \multicolumn{3}{|l|}{ Financial Aid } \\
\hline No & 118 & \\
\hline Fellows & 35 & \\
\hline ProUni & 50 & \\
\hline FIES & 50 & \\
\hline Quota Student & 3 & \\
\hline \multicolumn{3}{|c|}{ Teaching Experience } \\
\hline Up to 2 years & 15 & \\
\hline From 3 to 5 years & 18 & \\
\hline From 6 to 8 years & 9 & \\
\hline Over 9 years & 26 & \\
\hline
\end{tabular}

Source: Research Data.

\section{Quantitative Analysis of the Perception of Interprofessional Education by Students and Teachers}

Regarding comparing the development of students' collaborative competencies by course, there were no significant differences, as described in Table 2. 
Table 2

Comparison of the development of students' collaborative competencies by health area course

\begin{tabular}{|c|c|c|c|c|c|c|c|c|c|}
\hline Courses & $\mathrm{n}$ & $\begin{array}{l}\text { TAC } \\
\text { M(dp) } \\
(16-70)\end{array}$ & p-value & $\begin{array}{l}\text { IP } \\
M(d p) \\
(8-40)\end{array}$ & p-value & $\begin{array}{l}P C C \\
M(d p) \\
(5-25)\end{array}$ & p-value & $\begin{array}{l}\text { TOTAL } \\
\text { M(dp) } \\
(27-135)\end{array}$ & p-value \\
\hline Physiotherapy & 72 & $59.9(9.6)$ & \multirow[t]{3}{*}{0.10} & $30.9(2.9)$ & \multirow[t]{3}{*}{0.27} & 23.1(3.1) & \multirow[t]{3}{*}{0.43} & 114.1(13.8) & \multirow[t]{3}{*}{0.32} \\
\hline Medicine & 69 & $59.3(7.5)$ & & $30.1(2.9)$ & & $23.7(1.7)$ & & 113.2(9.9) & \\
\hline Nursing & 115 & $61.7(6.9)$ & & $30.5(3.1)$ & & $23.3(2.5)$ & & $115.7(10.5)$ & \\
\hline
\end{tabular}

*ANOVA * $p \leq 0.05$

Legend: TAC $=$ Teamwork and collaboration, $\mathrm{PI}=$ Professional identity, $\mathrm{PCA}=$ Patient-centered care, $\mathrm{M}=\mathrm{mean}, \mathrm{SD}=\mathrm{standard}$ deviation $=\mathrm{n}=$ number of participants

According to Table 3, in factor 1 , women presented significantly higher teamwork and collaboration (TAC) than men ( $p=0.03)$. No significant differences were observed in the other factors of professional identity (PI) and patient-centered care (PCC). 
Table 3

Collaborative competencies by gender, age, semester, financial support programs, interprofessional projects, and education

\begin{tabular}{|c|c|c|c|c|c|c|c|c|c|}
\hline Features & $\mathrm{n}$ & $\begin{array}{l}\text { TAC } \\
M(d p) \\
(16-70)\end{array}$ & $\begin{array}{l}\mathrm{p}- \\
\text { value }\end{array}$ & $\begin{array}{l}\mathrm{PI} \\
\mathrm{M}(\mathrm{dp}) \\
(8-40)\end{array}$ & $\begin{array}{l}\mathrm{p}- \\
\text { value }\end{array}$ & $\begin{array}{l}\text { PCC } \\
M(d p) \\
(5-25)\end{array}$ & p-value & $\begin{array}{l}\text { TOTAL } \\
\text { M(dp) } \\
(27-135)\end{array}$ & p-value \\
\hline \multicolumn{10}{|l|}{$\xi_{\text {Sex }}$} \\
\hline Female & 200 & $61.1(7.9)$ & \multirow[t]{2}{*}{$0.03^{*}$} & $30.6(3.1)$ & \multirow[t]{2}{*}{0.69} & $23.4(2.6)$ & \multirow[t]{2}{*}{0.45} & $115.2(11.6)$ & \multirow[t]{2}{*}{0.07} \\
\hline Male & 56 & $58.6(7.9)$ & & $30.4(2.8)$ & & $23.2(2.2)$ & & $112.2(10.3)$ & \\
\hline \multicolumn{10}{|l|}{ *Age group } \\
\hline 20-24 years old & 178 & $61.1(7.2)$ & \multirow[t]{5}{*}{0.07} & $31.0(2.8)^{\mathrm{a}}$ & \multirow[t]{5}{*}{$0.01^{*}$} & $23.6(2.3)^{b}$ & \multirow[t]{5}{*}{$\mathrm{p} \leq 0.001^{*}$} & $\begin{array}{l}115.8(10.9) \\
b\end{array}$ & \multirow[t]{5}{*}{$\mathrm{p} \leq 0.001^{*}$} \\
\hline $25-29$ years old & 52 & $60.7(7.4)$ & & $29.6(2.8)^{a}$ & & $23.2(1.9)^{c}$ & & $113.6(9.3)$ & \\
\hline $30-34$ years old & 14 & $59.2(7.6)$ & & 29.7(3.1) & & $23.6(1.6)^{d}$ & & $112.6(8.4)$ & \\
\hline $35-39$ years old & 7 & $54.5(18.0)$ & & $28.8(6.0)$ & & $\begin{array}{l}19.7(7.2) \\
\text { b.c.d }\end{array}$ & & $\begin{array}{l}103.1(30.9) \\
\mathrm{b}\end{array}$ & \\
\hline$>40$ years old & 5 & $52.6(12.4)$ & & $29.2(2.9)$ & & $22.0(2.4)$ & & $103.8(17.1)$ & \\
\hline \multicolumn{10}{|l|}{$\S$ Semester course } \\
\hline Penultimate & 114 & $60.2(8.9)$ & \multirow[t]{2}{*}{0.54} & $30.5(3.4)$ & \multirow[t]{2}{*}{0.96} & $23.4(3.0)$ & \multirow[t]{2}{*}{0.91} & $114.2(13.3)$ & \multirow[t]{2}{*}{0.65} \\
\hline Last & 142 & $60.8(7.1)$ & & $30.5(2.7)$ & & $23.4(2.1)$ & & $114.9(9.5)$ & \\
\hline \multicolumn{10}{|l|}{ *Programs } \\
\hline No & 118 & $59.6(8.1)$ & \multirow[t]{5}{*}{0.49} & $30.1(3.1)$ & \multirow[t]{5}{*}{0.26} & $23.1(2.7)$ & \multirow[t]{5}{*}{0.59} & $113.0(11.8)$ & \multirow[t]{5}{*}{0.30} \\
\hline Scholarship student & 35 & $61.0(10.2)$ & & $30.8(3.0)$ & & $23.2(3.5)$ & & $115.2(15.0)$ & \\
\hline ProUni & 50 & $61.3(6.8)$ & & $30.9(2.7)$ & & $23.7(1.6)$ & & $115.9(8.3)$ & \\
\hline FIES & 50 & $61.7(7.0)$ & & $30.9(3.0)$ & & $23.7(1.8)$ & & $116.4(9.9)$ & \\
\hline Quota Student & 3 & $63.0(2.6)$ & & $32.6(3.2)$ & & $23.3(2.8)$ & & $119.0(7.5)$ & \\
\hline \multicolumn{10}{|l|}{$\begin{array}{l}\text { *Interprofessional } \\
\text { project }\end{array}$} \\
\hline I do not participate & 238 & $60.3(8.1)$ & \multirow[t]{4}{*}{0.20} & $30.5(3.1)$ & \multirow[t]{4}{*}{0.38} & 23.41 & \multirow[t]{4}{*}{0.71} & $114.3(11.6)$ & \multirow[t]{4}{*}{0.49} \\
\hline Extension & 9 & $63.6(3.8)$ & & $31.7(2.0)$ & & 23.33 & & $118.7(6.3)$ & \\
\hline Education & 4 & $66.0(0.8)$ & & $30.5(2.3)$ & & 22.75 & & $119.2(4.0)$ & \\
\hline Search & 5 & $64.4(4.3)$ & & $28.8(1.0)$ & & 24.60 & & $117.8(5.3)$ & \\
\hline \multicolumn{10}{|l|}{ \&Other training } \\
\hline Yes & 206 & $60.9(7.6)$ & \multirow[t]{2}{*}{0.26} & $30.7(2.8)$ & \multirow[t]{2}{*}{$0.03^{*}$} & $23.6(2.1)$ & \multirow[t]{2}{*}{$\mathrm{p} \leq 0.001^{*}$} & $115.3(10.4)$ & \multirow[t]{2}{*}{$0.04^{\star}$} \\
\hline No & 50 & $59.5(9.3)$ & & $29.7(3.5)$ & & $22.3(3.5)$ & & $111.6(14.6)$ & \\
\hline
\end{tabular}

Regarding the age group in the PI factor (Table 3), the youngest between 20 to 24 years presented significantly higher scores than those in the 25 to 29 years age group ( $p=0.01$ ). Regarding the PCC factor, the older learners between 35 to 39 years were lower than those in the 20 to 24 years ( $p \leq 0.001), 25$ to 29 years $(p=0.005)$, and 30 to 34 years $(p=0.006)$ age groups. In the item Total Score, the 20 to 24 years group also presented higher values than the students between 35 to 39 years $(p=0.0290)$. The students with other previous education presented significantly higher scores compared to those who have no other education in the factors IP $(p=0.03), P C C\left(p \leq 0.001^{\star}\right)$, and the Total Score 
(0.04). There was no significant difference regarding the semester in a course, the programs they participate in, the interprofessional projects they participate in (Table 3).

Table 3

When comparing the training of the teachers of the three health courses, there was a significant difference in the PCC (Table 4), a significantly greater difference in Medicine compared to Physiotherapy ( $p=0.05)$, and in Nursing compared to Physiotherapy ( $p=0.02)$.

Table 4

Comparison of the development of teachers' collaborative competencies by health area course

\begin{tabular}{|c|c|c|c|c|c|c|c|c|c|}
\hline Courses & $\mathrm{n}$ & $\begin{array}{l}\text { TAC } \\
\text { M(dp) } \\
(16-70)\end{array}$ & p-value & $\begin{array}{l}\text { PI } \\
M(d p) \\
(8-40)\end{array}$ & p-value & $\begin{array}{l}P C C \\
M(d p) \\
(5-25)\end{array}$ & p-value & $\begin{array}{l}\text { TOTAL } \\
\text { M(dp) } \\
(27-135)\end{array}$ & p-value \\
\hline Medicine & 29 & $62.7(4.3)$ & 0.13 & $32.0(3.7)$ & 0.30 & $24.0(1.4)^{a}$ & $0.01 *$ & $118.8(6.9)$ & 0.33 \\
\hline Nursing & 17 & $60.8(5.3)$ & & $31.2(5.3)$ & & $24.2(0.9)^{\mathrm{b}}$ & & $116.4(7.8)$ & \\
\hline Physiotherapy & 22 & $63.9(2.8)$ & & $33.4(4.2)$ & & $22.8(2.4)^{a . b}$ & & $120.2(6.3)$ & \\
\hline
\end{tabular}

ANOVA, Tukey's post hoc * $p \leq 0,05$

Legend: TAC = Teamwork and collaboration, $\mathrm{PI}=$ Professional identity, $\mathrm{PCC}=$ Patient-centered care, ProUni $=$ University for all Program, FIES = Student financing

a Difference between Medicine and Physiotherapy - $p=0.05$

b Difference between Nursing and Physical Therapy - $p=0.02$

Women had higher scores in the Teamwork and Collaboration factor than men $(p=0.01)$. There were no significant differences in collaborative competencies among age groups, teaching time, and experience in interprofessional education. Among the teachers who participate in interprofessional projects, the group that does not participate in any such project had higher scores in the PCC factor than the research group $(p=0.009)$ (Table 5). 
Table 5

Development of collaborative competencies by gender, age group, teaching time, project participation, and interprofessional education

\begin{tabular}{|c|c|c|c|c|c|c|c|c|c|}
\hline Features & $\mathbf{n}$ & $\begin{array}{l}\text { TAC } \\
\text { M(dp) } \\
(16-70)\end{array}$ & $\begin{array}{l}\text { p- } \\
\text { value }\end{array}$ & $\begin{array}{l}P I \\
M(d p) \\
(8-40)\end{array}$ & $\begin{array}{l}\mathrm{p}- \\
\text { value }\end{array}$ & $\begin{array}{l}P C C \\
M(d p) \\
(5-25)\end{array}$ & $\begin{array}{l}\text { p- } \\
\text { value }\end{array}$ & $\begin{array}{l}\text { TOTAL } \\
\text { M(dp) } \\
(27-135)\end{array}$ & $\begin{array}{l}\mathrm{p}- \\
\text { value }\end{array}$ \\
\hline \multicolumn{10}{|l|}{ ssex } \\
\hline Female & 52 & $63.3(3.9)$ & \multirow[t]{2}{*}{$0.01 *$} & $32.6(4.6)$ & \multirow[t]{2}{*}{0.30} & 23.6(1.9) & \multirow[t]{2}{*}{0.25} & $119.5(6.6)$ & \multirow[t]{2}{*}{0.06} \\
\hline Male & 16 & $60.3(4.7)$ & & $31.3(3.4)$ & & $24.1(1.1)$ & & $115.8(7.7)$ & \\
\hline \multicolumn{10}{|l|}{ *Age group } \\
\hline $30-34$ years old & 11 & $63.1(2.4)$ & \multirow[t]{3}{*}{0.28} & $34.3(1.9)$ & \multirow[t]{3}{*}{0.16} & $23.6(2.6)$ & \multirow[t]{3}{*}{0.30} & $121.1(4.0)$ & \multirow[t]{3}{*}{0.44} \\
\hline $35-39$ years old & 15 & $64.0(2.2)$ & & $31.0(4.1)$ & & $23.1(2.2)$ & & $118.2(4.8)$ & \\
\hline$>40$ years old & 42 & $62.0(5.1)$ & & $32.2(4.8)$ & & $23.9(1.2)$ & & $118.2(8.1)$ & \\
\hline \multicolumn{10}{|l|}{ *Time of teaching } \\
\hline Up to 2 years & 15 & $61.0(4.5)$ & \multirow[t]{4}{*}{0.27} & $31.9(3.2)$ & \multirow[t]{4}{*}{0.78} & $23.1(2.4)$ & \multirow[t]{4}{*}{0.40} & $116.0(6.5)$ & \multirow[t]{4}{*}{0.40} \\
\hline From 3 to 5 years & 18 & $63.9(2.3)$ & & $31.6(4.2)$ & & $23.6(1.7)$ & & $119.2(6.0)$ & \\
\hline From 6 to 8 years & 9 & $63.1(4.3)$ & & $33.1(4.5)$ & & $24.3(0.8)$ & & $120.5(6.2)$ & \\
\hline Over 9 years & 26 & $62.5(5.0)$ & & $32.7(5.0)$ & & $23.9(1.5)$ & & 119.1(8.0) & \\
\hline \multicolumn{10}{|c|}{ *Interprofessional project } \\
\hline I do not participate & 43 & $62.1(4.0)$ & \multirow[t]{4}{*}{0.58} & $32.3(4.5)$ & \multirow[t]{4}{*}{0.94} & $24.0(1.1)^{a}$ & \multirow[t]{4}{*}{$0.01 *$} & $118.6(7.1)$ & \multirow[t]{4}{*}{0.77} \\
\hline Extension & 3 & 65.3(1.) & & $31.6(4.1)$ & & $23.6(1.1)$ & & $120.6(4.1)$ & \\
\hline Education & 12 & $63.1(4.1)$ & & $32.7(5.0)$ & & $23.9(1.7)$ & & $119.8(6.6)$ & \\
\hline Search & 10 & $63.2(6.2)$ & & $31.7(3.5)$ & & $22.1(3.2)^{a}$ & & $117.0(7.8)$ & \\
\hline \multicolumn{10}{|c|}{$\begin{array}{l}\mathcal{S} \text { Experience in Inter vocational } \\
\text { education }\end{array}$} \\
\hline No & 18 & $62.0(3.6)$ & \multirow[t]{2}{*}{0.46} & $33.2(3.3)$ & \multirow[t]{2}{*}{0.30} & $23.6(2.3)$ & \multirow[t]{2}{*}{0.73} & $118.8(1.4)$ & \multirow[t]{2}{*}{0.92} \\
\hline Yes & 50 & $62.8(4.5)$ & & $31.9(4.6)$ & & $23.7(1.6)$ & & 118.6(1.0) & \\
\hline
\end{tabular}

*Annova, Tukey's post hoc * ${ }^{*} \leq 0,05$

$\S$ T Student ${ }^{*} p \leq 0,05$

Legend: TAC $=$ Teamwork and collaboration, $\mathrm{PI}=$ Professional identity, $\mathrm{PCC}=$ Patient-centered care, ProUni $=$ University for all Program, FIES = Student financing

a Significant difference between the experience in interprofessional education (PCC - $p=0.009)$

There were no significant differences between TAC ( $p=0.19)$ and PCC (0.65) when comparing teachers and students. In the items PI ( $\leq 0.001)$ and Total Score, the teachers (0.04) were higher than the students (Figure 3 ).

\section{Discussion}

This study explores the perception of teachers and final-year students of Nursing, Physiotherapy, and Medicine courses at a private university in São Paulo regarding the leading knowledge and attitudes for readiness for interprofessional learning.

The results indicate no significant differences when comparing the students' collaborative skills development in each course. These findings align with those of Maharajan et al. [16]. The mean scores for the RIPLS domains of "teamwork and collaboration," "positive professional identity," and their "roles and responsibilities" did not differ among the students on different courses. This demonstrates that students from all 
courses were ready for teamwork, encouraging positive professional relationships. To better understand the role of other health professionals in the health care team, each health care student should understand their own professional identity at the early stage of their career.

Regarding teamwork and collaboration, data from the literature regarding gender is added and indicates that women have more significantly positive attitudes toward this factor in RIPLS. Some studies from Sweden $[17,18]$ that used the RIPLS or the Jefferson scale, which is a scale of attitudes related to interprofessional collaboration, also reveal more positive attitudes towards teamwork in women. Berger-Estilita et al. [19] used the G-IPAS (German Interprofessional Attitudes Scale) and observed more positive attitudes in women in teamwork, roles, and responsibilities and patient-centered care and the scale overall. The finding of this study concerned both students and teachers.

Hansson, Foldevi, and Mattsson [17] compared the attitudes of first- and final-year students of Nursing and Medicine concerning the development of collaborative competencies and observed that both professions had the same attitude toward collaboration. These findings are in line with the results of the current study. The development of collaborative competencies of students from Physiotherapy, Nursing, and Medicine courses did not exhibit differences in collaboration. However, other studies present different results, indicating that nursing students seemed to welcome teamwork and collaboration more than medical students $[18,20]$.

When comparing the training of nursing, physiotherapy, and medical teachers, there was a difference in the development of collaborative competencies in patient-centered care, observing that medical teachers display more willingness toward collaborative attitudes than physiotherapy teachers, and nursing teachers also showed higher scores in collaborative competencies than physiotherapy teachers. The findings in the literature indicate that nurses have a better attitude toward interprofessional collaboration and education than other health professionals [21] and that Medical teachers score lower than Nursing teachers on attitude towards IPE [22]. In a similar study, nursing teachers were also reported to have a more favorable attitude than any other profession [23]. Nurses' positive attitude toward interprofessional health teams and IPE may be due to the nature of the profession, which requires constant cooperation with other people and professionals in the performance of their duties, and due to the Nursing profession's higher expectation of obtaining better results with IPE to improve the quality of collaboration among health teams. Meanwhile, the characteristics of medical education, which emphasize the importance of independence and trust in care practice, may influence less willingness toward interprofessional collaborative work and education of professionals [14].

Prentice et al. [24] observed that medical students had more exposure to organized IPE events because it is part of the curriculum and, therefore, were more critical than nursing students and expressed better expectations of IPE. On the other hand, students of Nursing had no previous formalized experiences in IPE and, therefore, are unaware of the objectives of IPE or its importance and satisfaction with its realization in events [24]. These data corroborate the findings of the current study when we observe the pedagogical projects and the curricular matrix of the courses, in which the Medicine course has a greater emphasis on the menus and the arrangement of the curricular units concerning interprofessional activities during the learning path of their training. Another fact that can add to these findings is that the students are in their last year of the course and have internships in hospitals and integrated clinics. In these clinical rotations, students have the chance to communicate, interact, and work as a team with each other and with the hospital staff at different levels.

Other results compare students who have previous experiences or attended other higher education courses with those who do not. It was found that those who have experience in the factors of professional identity, patient-centered care, and the total score displayed higher results than those who do not have other previous academic training or experience. These data added to the literature [24] indicate that the greater the exposure to interprofessional activities and previous experiences, students recognize the objectives of the IPE, have more clinical goals, autonomy concerning their professional identity, positive attitudes, and availability to understand the patient's needs.

Santos, Simonetti, and Cyrino [25] conducted qualitative research with undergraduate students in the Health area that sought to understand the experience of these interlocutors with the IPE in the disciplines of university-service-community interaction. Students of Medicine and Nursing reported positive experiences in health services and primary health units with good examples of collaborative practices due to the opportunity to learn together, share knowledge, and follow the joint action of team members from different professions.

Santos, Simonetti, and Cyrino [25] presented the theme of the teacher as a mediator of the teaching-learning process. This expresses how many interlocutors recognize the teacher as having an essential role in enabling and strengthening the IPE in the daily life of the disciplines. Here, there is a challenge for the teacher because, while needing to value the singularities of the different health professions and their complementarity in the team action, they also need to deal with the solid uniprofessional identities of some students who perceive the IPE and collaborative practice as threats to their professional limits [26]. IPE demands a continuous and critical teacher education process, given that "one learns to teach from the perspective of IPE, teaching, and to reflect on the experiences, building knowledge, strategies, and collective projects" [27].

As strengths of this study, we can highlight the application of the questionnaires with teachers and students, in addition to the analysis of the academic documentation of the courses, since the study models in the area are in general segmented in the aspect of the target audience and 
added to the academic documentation. Its weaknesses may be that it was conducted only at a private university in São Paulo and the data analysis was limited to this population and documents. Another limitation may have been the number of courses studied at this university. It offers 16 courses in the health area that integrate some academic activities.

\section{Conclusion}

We explored the perceptions of students and teachers of Nursing, Physiotherapy, and Medicine on the knowledge and experiences of IPE in their training. This research revealed that Medicine and Nursing training have greater ease for interprofessional education than training in Physiotherapy. The fact that the type of training of these professions is more focused on team interaction may explain this finding.

When comparing the perception of the academic community concerning gender, it is evident that female participants present a greater willingness to engage in teamwork and collaborative practices. This evidence may be related to the fact that women nowadays have positions and expectations similar to men in the labor market, contributing to the collaborative spirit. However, this issue should be examined in greater depth in future research.

To improve the perception of students and teachers in collaborative practice, the need for a teacher training program on IPE principles and an early and more frequent insertion of IPE practices in the curricula of courses is evident. The study concludes that it is necessary to mobilize actors from educational institutions and health services to discuss and collectively build educational projects that promote interprofessional training.

\section{Abbreviations}

HEls

higher education institutions

ICF

informed consent form

IPE

interprofessional education

$\mathrm{MH}$

Ministry of Health

MEC

Ministry of Education

PAHO

Pan American Health Organization

PCC

patient-centered care

$\mathrm{PI}$

professional identity

$\mathrm{PIH}$

Partners in Health

ReBETIS

Brazilian Network of Education and Interprofessional Health Work

RIPLS

Readiness for Interprofessional Learning Scale

HUS

Health Unic System

TAC

teamwork and collaboration

\section{Declarations}

\section{Acknowledgements}

Not necessary.

\section{Authors' contributions}


All authors conceived the idea presented. L.G.A.V. carried out the experiment.

L.G.A.V. and P.Z.T developed the theory. L.G.A.V. and P.Z.T wrote the methods section.

L.G.A.V., A.O.S. and P.Z.T. conducted the analyses and wrote the results section. All

authors collaborated on the discussion section. All authors discussed the

results and contributed to the final manuscript. A.O.S. and P.Z.T. supervised the

conceptualization and process of writing the paper. All authors read and

approved the final manuscript.

\section{Funding}

The authors did not receive support from any organization for the submitted

work.

\section{Availability of data and materials}

The datasets used and/or analyzed during the current study are available from the corresponding author on reasonable request.

E-Mail: luciana.auad@usp.br

\section{Ethics approval and consent to participate}

All procedures in this study were performed in accordance with the ethical standards of the German Psychological Society, of the 1964 Helsinki Declaration and its later amendments and were approved by the Research Ethics Committee of the Medical School of the Universidade de São Paulo approved the research (\#3.011.083). Informed consent was obtained from all individual participants included in the study.

\section{Consent for publication}

Not applicable.

\section{Competing interests}

All authors declare that there are no conflicts of interest.

\section{References}

1. Lary MJ, Lavigne SE, Muma RD, Jones SE, Hoeft HJ. Breaking down barriers: multidisciplinary educational model. J Allied Health. 1997;26(2):63-9. https://soar.wichita.edu/bitstream/handle/10057/4931/Breaking\%20Down\%20Barriers.pdf?sequence=3

2. Khan NS, Shahnaz SI, Gomathi KG. Currently available tools and teaching strategies for the interprofessional education of students in health professions. Sultan Qaboos Univ Med J. 2016;16(3):e227-e285. https://dx.doi.org/10.18295\%2Fsqumj.2016.16.03.003

3. Peduzzi M, Norman IJ, Germani ACCG, Silva JAM, Souza GC. Interprofessional education: training health professionals for teamwork with a focus on users.Rev Esc Enferm USP. 2013;47(4):977-83. https://doi.org/10.1590/S0080-623420130000400029

4. Frenk J, Chen L, Bhutta ZA, Cohen J, Crisp N, Evans T, et al. Health professionals for a new century: transforming education to strengthen health systems in an interdependent world.Lancet. 2010;376(9756):1923-58. https://doi.org/10.1016/s0140-6736(10)61854-5

5. World Health Organization. Framework for action on interprofessional education and collaborative practice. Geneva: World Health Organization; 2010.

http://apps.who.int/iris/bitstream/handle/10665/70185/WHO_HRH_HPN_10.3_eng.pdf;jsessionid=6F45849AEEA6090F2E3823997DA9CBFE? sequence $=1$

6. Barr H. Competent to collaborate: towards a competency-based model for interprofessional education. J Interprof Care. 1998;12(2):181-

8. https://neipc.ufes.br/sites/neipc.ufes.br/files/field/anexo/competent_to_collaborate.pdf

Page $12 / 15$ 
7. Barr H. Interprofessional education: today, yesterday and tomorrow: a review. London: Higher Education Academy, Health Sciences and Practice Network; 2005. https://www.unmc.edu/bhecn/_documents/ipe-today-yesterday-tmmw-barr.pdf

8. Reeves S, Xyrichis A, Zwarenstein, M. Teamwork, collaboration, coordination, and networking: Why we need to distinguish between different types of interprofessional practice.J Interprof Care. 2018;32(1):1-3. https://doi.org/10.1080/13561820.2017.1400150

9. Silva JAM, Peduzzi M, Orchard C, Leonello VM. Interprofessional education and collaborative practice in Primary Health Care.Rev Esc Enferm USP. 2015;49(suppl 2):16-24. https://doi.org/10.1590/S0080-623420150000800003

10. Germani ACCG, Oliver FC, Rocha EF, Carvalho YM, Peduzzi M, Sangaleti C. Learning to work together: challenges in teaching interprofessional and collaborative practice. Convibra Management, Education and Health Promotion; 2013.

11. Freire Filho JR, Silva CBG, Costa MV, Forster AC. Interprofessional education in the policies of reorientation of professional training in health in Brazil. Saúde Debate. 2019;43(1):86-96. https://doi.org/10.1590/0103-11042019S107

12. Reeves S. Why we need interprofessional education to improve the delivery of safe and effective care. Interface (Botucatu). 2016;20(56)

13. Costa MV. The interprofessional education in Brazilian context: some reflections.Interface (Botucatu). 2016;20(56):197-8. https://doi.org/10.1590/1807-57622015.0311

14. Parsell G, Bligh J. The development of a questionnaire to assess the readiness of health care students for interprofessional learning (RIPLS).Med Educ. 1999;33(2):95-100. https://doi.org/10.1046/j.1365-2923.1999.00298.x

15. Peduzzzi M, Norman I, Coster S, Meireles E. Cross-cultural adaptation and validation of the Readiness for Interprofessional Learning Scale in Brazil.Rev Esc Enferm USP. 2015;49(Esp2):7-15. https://doi.org/10.1590/S0080-623420150000800002

16. Maharajam MK, Rajiah K, Khoo SP, Chellappan, Alwis RD, Chui HC, et al. Attitudes and

readiness of students of healthcare profession stowards interprofessional learning.PLoS One.

2017;12(1):e0168863. https://doi.org/10.1371/journal.pone.0168863

17. Hansson A, Foldevi M, Mattson B. Medical students' attitudes toward collaboration between doctors and nurses - a comparison between two Swedish universities.J Interprof Care. 2010;24(3):242-50. https://doi.org/10.3109/13561820903163439

18. Wilhelmsson M, Ponzer S, Dahlgren LO, Timpka T, Faresjo T. Are female students in general and nursing students more ready for teamwork and interprofessional collaboration in healthcare?.BMC Med Educ. 2011;11:15.

19. Berger-Estilita J, Chiang H, Stricker D, Fuchs A, Greif R, McAleer S. Attitudes of medical students towards interprofessional education: a mixed-methods study.PLoS One. 2020;15(10): e0240835. https://doi.org/10.1371/journal.pone.0240835

20. Hind M, Norman I, Cooper S, Gill E, Hilton R, Judd P, et al.Interprofessional perceptions of health care students. J Interprof Care. 2003. 17(1):21-34. https://doi.org/10.1080/1356182021000044120

21. Lestari E, Stalmeijer RE, Widyandana D, Scherpbier A. Understanding attitude of health care professional teachers toward interprofessional health care collaboration and education in a southeast Asian country.J Multidiscip Healthc. 2018; 11:557-

71. https://doi.org/10.2147/jmdh.s178566

22. Curran VR, Sharpe D, Forristall J. Attitudes of health sciences faculty members towards interprofessional teamwork and education.Med Educ. 2007;41(9):892-6. https://doi.org/10.1111/j.1365-2923.2007.02823.x

23. Hoffman J, Redman-Bentley D. Comparison of faculty and student attitudes toward teamwork and collaboration in interprofessional education.J Interprof Care. 2012;26(1):66-8. https://doi.org/10.3109/13561820.2011.602441

24. Prentice D, Engel J, Taplay K, Stobbe K. Interprofessional collaboration: the experience of nursing and medical students' interprofessional education. Glob Qual Nurs Res. 2015;2: 2333393614560566.. https://doi.org/10.1177/2333393614560566

25. Santos LC, Simonetti JP, Cyrino AP. Interprofessional education in the undergraduate Medicine and Nursing courses in primary health care practice: the students' perspective.Interface (Botucatu). 2018;22(Suppl. 2):1601-11. https://doi.org/10.1590/1807-57622017.0507 
26. Khalili H, Orchard C, Laschinger HK, Farah R. An interprofessional socialization framework for developing an interprofessional identity among health professions students.J Interprof Care. 2013;27(6):448-53. https://doi.org/10.3109/13561820.2013.804042

27. Batista NA, Batista SHSS. Interprofessional education in health training: weaving networks of practices and knowledge.Interface (Botucatu). 2016;20(56):202-4. https://doi.org/10.1590/1807-57622015.0388

\section{Figures}

\section{Flowchart for Student Losses}

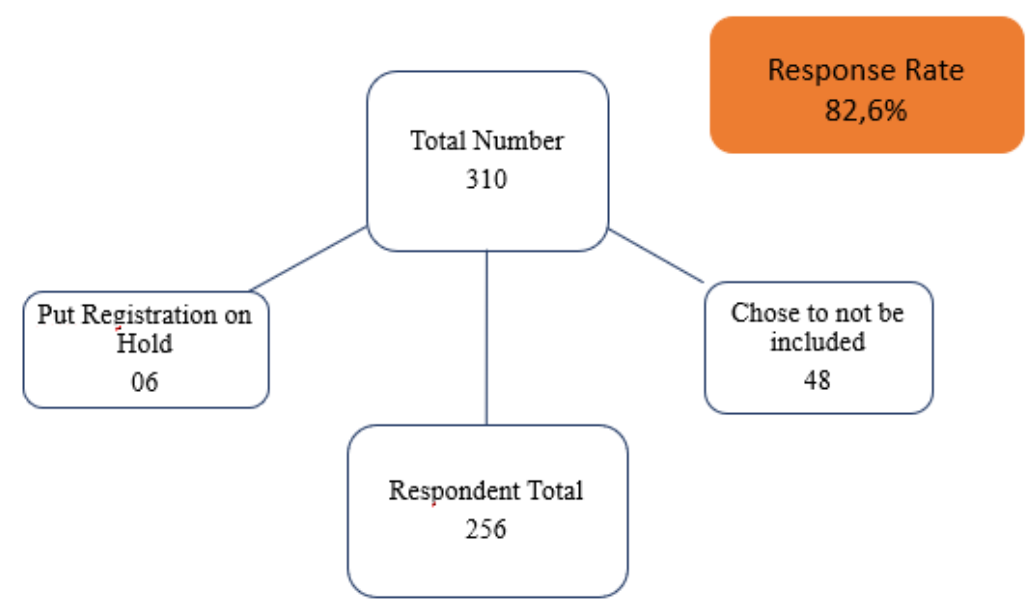

Figure 1

Flowchart of losses for teaching students.

Source: Research Data.

\section{Flowchart for Teacher Losses}

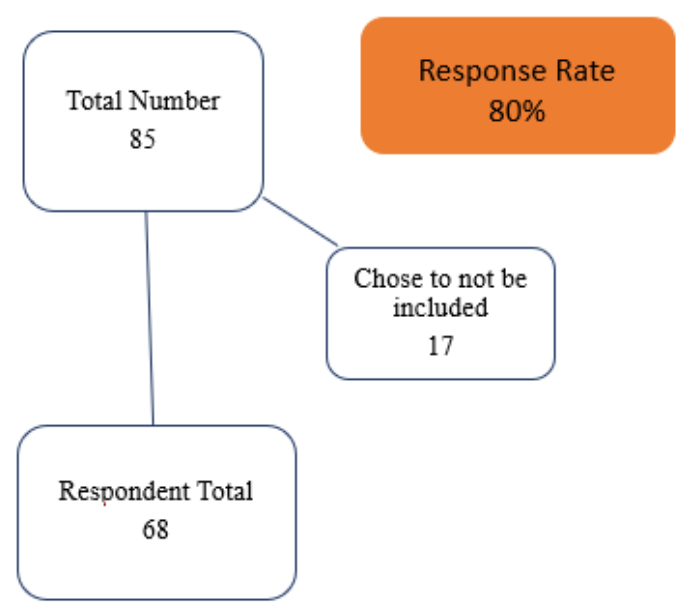

\section{Figure 2}

Flowchart of Teacher losses.

Source: Research Data. 

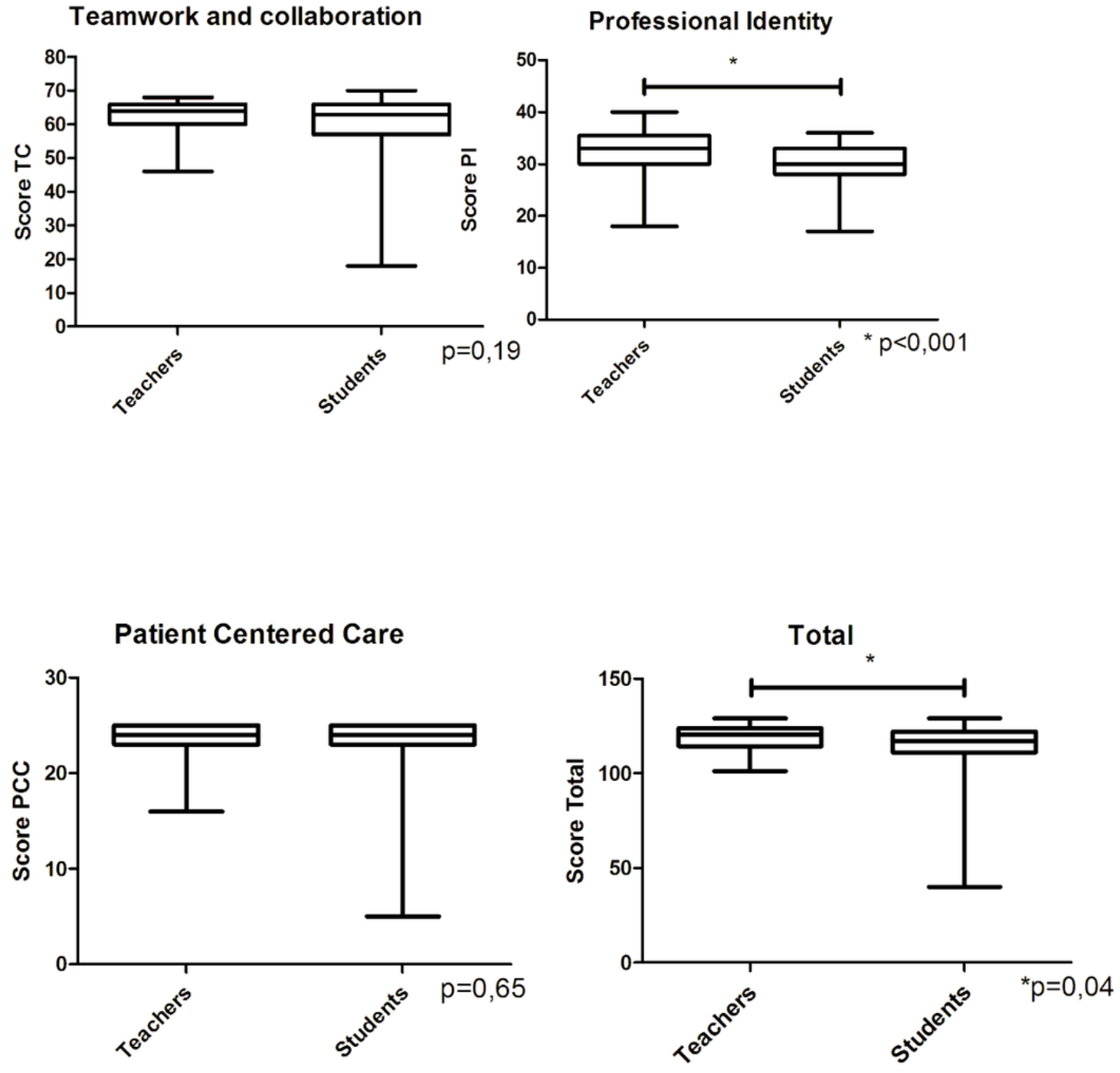

Figure 3

Comparison of the development of collaborative skills among teachers and students of the health courses.

Mann-Whitney U test; * $\mathrm{p} \leq 0.05$.

Source: Research Data. 